\title{
Electronic System for Managing Theses of Computer Science College
}

\author{
Auday H. Al-Wattar \\ ahsa.alwattar@uomosul.edu.iq \\ Dhafar H. Al-Ali \\ dhafar.csp82@student.uomosul.edu.iq \\ Department of Computer Science \\ College of Computer Science and Mathematics \\ University of Mosul, Mosul, Iraq
}

Received on: 07/02/2021

Accepted on: 09/03/2021

\begin{abstract}
This research paper includes designing and implementing of an Electronic system for managing theses of College of Computer Science and Mathematics, University of Mosul, using replication, C \# language and MS SQL Server 2008 databases to be a stable work basis that can be relied upon in the departments' work as it facilitates the higher administrative bodies in the departments and the deanship Obtaining the required results quickly and accurately, which facilitates and contributes to making the right decisions at the appropriate time and required with the ease of preparing special reports for each student, lecturer and thesis and printing them which it will help the departments head and the scientific committee to complete them if requested, as well as provide various statistics, and to improve administrative efficiency for thesis, the problem of losing thesis data and preserving it from human and natural disasters has been overcome by applying the principle of replication.
\end{abstract}

Keywords: Electronic Management, Theses and Dissertations, Replication, DBMS.

$$
\begin{aligned}
& \text { نظام إلكتروني لإدارة رسائل كلية علوم الحاسوب والرياضيات } \\
& \text { ظفر حسين العلي علي هاشم الوتار } \\
& \text { قسم علوم الحاسوب، كلية علوم الحاسوب واليرياضيات }
\end{aligned}
$$

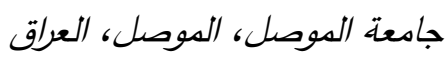

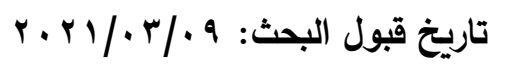

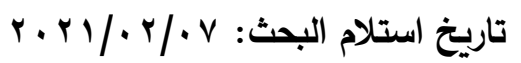

$$
\begin{aligned}
& \text { الملخص } \\
& \text { تتضمن الورقة البحثية تصميم وتتفيذ نظام الكتروني لإدارة رسائل كلية علوم الحاسوب والرياضيات جامعة الموصل } \\
& \text { باستعمال النسخ المتماثل الـ Replication ولغة C\# وقواعد البيانات MS SQL Server } 2008 \text { ليكون أساس عمل } \\
& \text { ثابت يمكن الاعتماد عليه في عمل القسم إذ يسهل للجهات الإدارية العليا في القسم والعمادة الحصول على النتائج }
\end{aligned}
$$

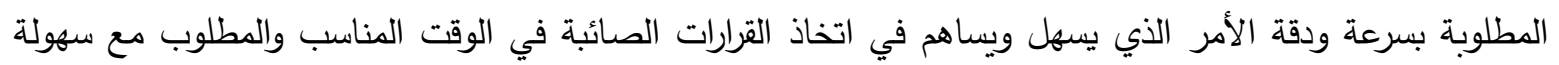

$$
\begin{aligned}
& \text { إعداد التقارير الخاصة لكل من الطالب، الأستاذ والأطروحة وطباعتها التي تساعد رئاسة القسم واللجنة العلمية إنجازها } \\
& \text { في حال طلبها فضلاً عن توفير إحصائيات منوعة، و لتحسين الكفاءة الإدارية للأطروحة والرسالة تم التغلب على مشكلة }
\end{aligned}
$$

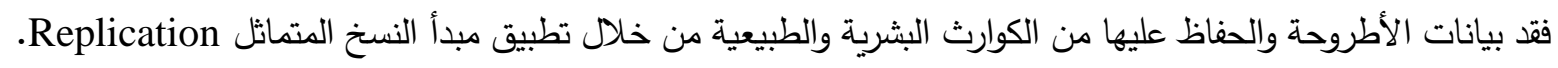


الكلمات المفتاحية: إدارة إلكترونية، رسائل وأطاريح، النسخ المتماثل، إدارة قواعد البيانات. الإطار العام للبحث

1. المقدمة

شهد العالم في العقود الأخيرة خاصة في الألفية الثالثة ثورة هائلة، وأدى عصر الحاسوب إلى العولمة السريعة والوصول السريع إلى المعلومة التي سهلت إدارة المعلومات للملفات الإكترونية وعمليات البحث واسترجاع ملفات البيانات وسرعة نسخها والوصول اليها ومتابعة سير العمل وتنظيم البيانات وتحديثها والجوانب الاخرى لتقنية المعلومات، وفي قسم الحاسوب بالرغم من تلك الاهمية التي تتمتع بها هذه البحوث الا ان اتاحتها بالثكل الرقمي في القسم المعني لا تتعدى سوى تزويد طلبة الدراسات العليا واساتذة القسم بأقراص مدمجة. إن الإتاحة الإكترونية للبحوث ستؤدي لتطوير التعليم الجامعي العالي وستعزز من سمعة الجامعات العلمية[2].

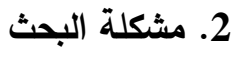

إن المشكلة الأساسية التي يعرضها هذا المشروع هو عدم وجود نظام إلكتروني في كلية علوم الحاسوب والرياضيات جامعة الموصل خاص بإدارة بحوث طلبة الدراسات العليا والاعتماد على النظام اليدوي التقليدي بمساعدة بعض التطبية الحاسوبية البسيطة والتي تعد وسائط بسيطة ووسائل مساعدة ثانوية لا يعول عليها في تكامل العمل وهذا النظام اليدوي التقليدي إضافة إلى كونه اصبح لا يلبي متطلبات القسم المتزايدة بعد الازدياد الكبير في اعداد الرسائل والأطاريح التي ينتجها كل عام فان النظام لله عيوب كبيرة واهمها هو إمكانية التلف والضياع والاندثار المككن حدوثه نتيجة لأي ظرف طارئ ولتجربة مدينة الموصل الأليمة والقاسية التي مرت بها في عام 2014 والظروف القاهرة التي مرت على جامعة الموصل والتلف والحرق الذي أصاب معظم المكاتب التي تحوي الأطاريح والرسائل خير مثال يدعو لإيجاد بديل ناجح يجعل بالإمكان الاحتفاظ بالأطاريح والرسائل وكل ما يتعلق بهم وإمكانية استخدامهم من أي مكان تحت أي ظرفي الإست 3. - أهداف البحث

يهدف البحث إلى تصميم وبناء نظام حاسوبي متكامل لإدارة الرسائل والأطاريح إلكترونياً ومتابعة حالة طالب

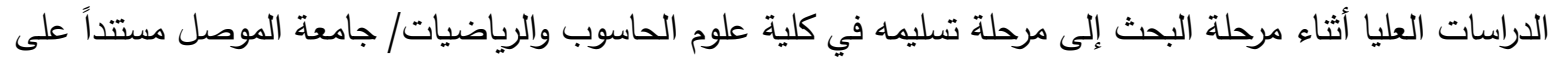

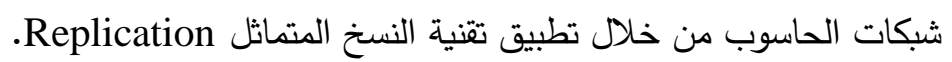

4. أهمية البحث

من خلال دراسة كلية علوم الحاسوب والرياضيات الحالي ظهرت الحاجة الملحة إلى بناء تطبيق حاسوبي، لإدارة البحوث الخاصة بطلبة الدراسات العليا وتتبع حالة طالب الدراسات العليا يكون قادر على استيعاب هذه الزيادة وتمكين العاملين عليه والباحثين على أقصى درجات الاستفادة من هذا النظام في ترتيب الاعمال الخاصة بالدراسات العليا

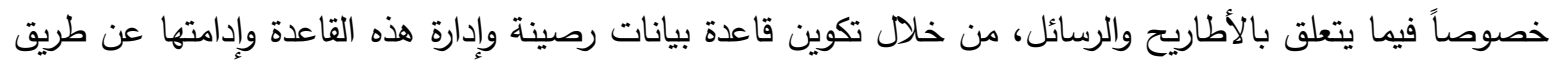
استخدام آليات هذا النظام الحاسوبي وبالثكل الذي يلبي متطلبات العمل وبصورة عملية وكفؤة. 
5. الدراسات السابقة ذات الصلة

يعد موضوع إدارة المعلومات البحثية الخاصة بالأطاريح والرسائل أحد المواضيع الحديثة في المجال البحثي وتوجه جديد للمؤسسات أو الجامعات بمختلف أنواعها، وقد ظهرت العديد من الدراسات والأبحاث العلمية التي تتاولت موضوع الإدارة الإكترونية للرسائل والأطاريح والتي سيتم سردها دون التطرق إلى التقنيات المتخصصة المستخدمة في كل منها كونها خارج الإطار الخاص بهذه الرسالة:

1.5

1- جاءت دراسـة الباحثة يسرى محمد الجدعاني [1] في عام 2011 بعنوان الارشفة الإلكترونية للرسـائل الجامعية في

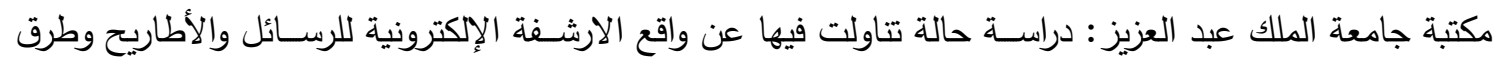
تطبيقها والمعوقات التي واجهتها.

2- وفي عام 2016 جاءت رسـالة الماجستير للباحث مازن محمد ابراهيم [3] من جامعة النيلين في السـودان لتناقش ونش بناء نظام إلكتروني لإدارة الأوراق العلمية لكلية الدراسات العليا بجامعة النيلين.

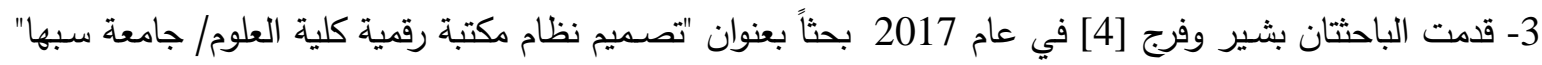
الهدف منـهُ تطوير مكتبة رقمية لكلية العلوم - جامعة ســــها تكون رائدة في تقديم الخدمات المعلوماتية من خلال الإنترنت. يقوم بتعريف المكاتب الرقمية وتمكين الأساتذة والطلاب الحصول على المعلومات في أي وقت ومكان. 4- أما الباحث كاظم زغير عودة [6] من جامعة بغداد/ كلية الاعلام وقدم بمشـاركة الأستاذ فضل عبد الرحيم عبد الله من جامعة النيلين في السودان بحثاً في عام 2019 بعنوان نظم المعلومات وأثرها على اتجاهات الباحثين في مجال الاعلام بناء قاعدة بيانات لرسـائل وأطاريح كلية الإعلام في جامعة بغداد للفترة من 2005-2015 الهدف منها هو قياس تأثير نظم المعلومات المحوسبة على اتجاهات الباحثين ويتم تحقيقها من خلال بناء نظام قاعدة بينات لرسائل وأطاريح مكتبة كلية الاعلام في جامعة بغداد وإدارة بياناتها .

2.5

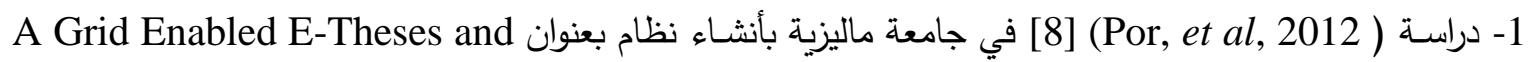
Dissertations Repository System بالوصول للرسالة عن بعد وباستخدام تقنية شبكات البيانات.

2- نشــرت دراســـة (Ysmael, et al, 2016) في جامعة De La Salle University في الفلبين بعنوان System (TCS) Design and Implementation of a Web-Based Thesis Coordinator وتتفيذ نظام إدارة وتتســيق الاطروحة الإكترونية يهدف إلى توفير نظام إدارة اطروحة فعال لقســم الحاســوب في الجامعة أعلاه كبيئة عمل.

3- صـمم STMIK IBBI الإندونيسـية نظاماً بعنوان Putra, 2020) [10] في جامعة Danta Manement System for Thesis Monitoring at STMIKIBBI Using B-Model 
باستخدام نموذج B-Model يساعد بمراقبة الرسالة من خلال تمكين التفاعل ما بين المشرف والطالب في حالة هناك عقبات تمنع تواصلهم وجهاً لوجه. إن الدراسات السابقة التي أُجريت في عدد من الدول العربية والاجنبية وفي الجامعات العراقية الاخرى تختلف ولاشك لهك مع بيئة الاعمال في قسم الحاسوب/ كلية علوم الحاسوب والرياضيات/ جامعة الموصل لذا فإن هذه الدراسة تعد من أوائل الدراسات التي سوف يتم إجراؤها على مستوى القسم للحصول على تطبيق إلكتروني حديث يعمل على إدارة الأطاريح والرسائل في هذا القسم وتحويل الاعتماد عليه بدلا من النظام اليدوي التقليدي من خلال استخدام احدث البرمجيات الخاصة بتصميم قواعد البيانات وبواجهات سلسة توفر أساليب دقيقة في استرجاع المعلومة المطلوبة من الأطاريح والرسائل وبأقصى سرعة ممكنة إضافة إلى الإمكانيات الكثيرة الأخرى التي يوفرها هذا النظام وخصوصا قابلية الخزن والحفاظ على المعلومات والبيانات ضد كل العوارض وفي كل الظروف من خلال توظيف الإمكانيات الإكترونية الحديثة المختلفة وعبر استخدام نظام النسخ المتماثل Replication من أجل الوصول إلى مستوى الاهمية التي يحظى بها تطبيق نظام الإدارة الإلكترونية لرسائل وأطاريح في قسم الحاسوب ومبررات التطبيق ومبادئه ومعوقاته.

\section{الخلفية والادوات المستخدمة في النظام}

(الإطار الخلفي)

2. 2. 2 إدارة بحوث طلبة الدراسات العليا

تعد البحوث على مستوى الماجستير والدكتوراه من أهم مصادر المعلومات التي تقتنيها المكتبات ومراكز المعلومات والمؤسسات الصناعية إذ تثكل مصدراً أولياً لا غنى للباحثين عنها في كل المجالات، لكونها تتتاول موضوعات منتوات أصيله لم يسبق بحثها او دراستها، إضافة الى الاستفادة من المعلومات المتخصصة في الموضوع الذي تتتاوله، وهي الأساس الذي استمدت وتستمد منه كل الإبتكارات العلمية والحضارية التي تم التوصل اليها في عصرنا الحالي[5].

Replication 3 النستخ المتماثل

يشير النسخ المتماثل Replication إلى توزيع قاعدة البيانات بين مواقع متعددة. ويعد وجود قواعد البيانات الموزعة

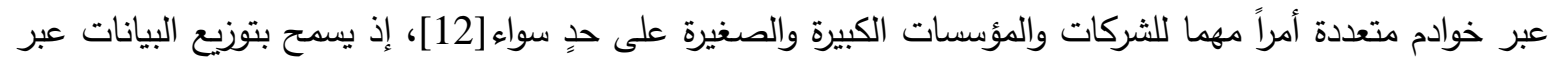

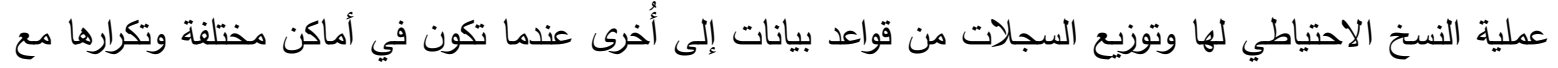
ضمان اتساقها وسلامتها، وتمكن تقنية Replication المتوفرة في إصدار 2008 MS SQL Server من إنشاء نسخة متطابقة من قاعدة البيانات الاساسية ومزامنة التغييرات التي حصلت على النسخة الاصلية بين قواعد البيانات المتعددة ليوفر خيارات متتوعة لحماية البيانات واستردادها عند الحاجة وتخزينها في اكثر من موقع. يمكن تعريف النسخ المتماثل بشكل آخر بأنه تقنية موزعة تقوم بنسخ وحفظ للمتغيرات التي حدثت في جداول قواعد البيانات المختلفة في النظام موزعة ملته على عدة خوادم لتحسين عملية الإدارة، تستخدم لتخزين البيانات في مواقع متعددة لتفادي فقدانها وزيادة وصول المستخدمين 
تحليل بيئة النظام وتصميمه

1. تحليل النظام المقترح

تم اتباع اسلوب تحليل النظام بعدد من الخطوات بدايةً بدراسة البنية التحتية لبيئة النظام شملت مكتبة قسم الحاسوب وتجميع كافة المعلومات والبيانات من الواقع الميداني ليتم تحديد تقانات المعلومات وبيان إمكانية الثروع بالتصميم وتتفيذ النظام في بيئة قسم الحاسوب ودعم النظام من خلال التحليل المتوافر لتقنيات المعلومات وتحديد جميع المتطلبات اللازمة لتصميم قاعدة البيانات وتحديد عدد الجداول والحقول ونوعها التي على أساسها صممت الواجهات بصورة أولية بواسطة المستلزمات المادية والبرمجية لإنجاز النظام واخيراً اختبار النظام وتتفيذه.

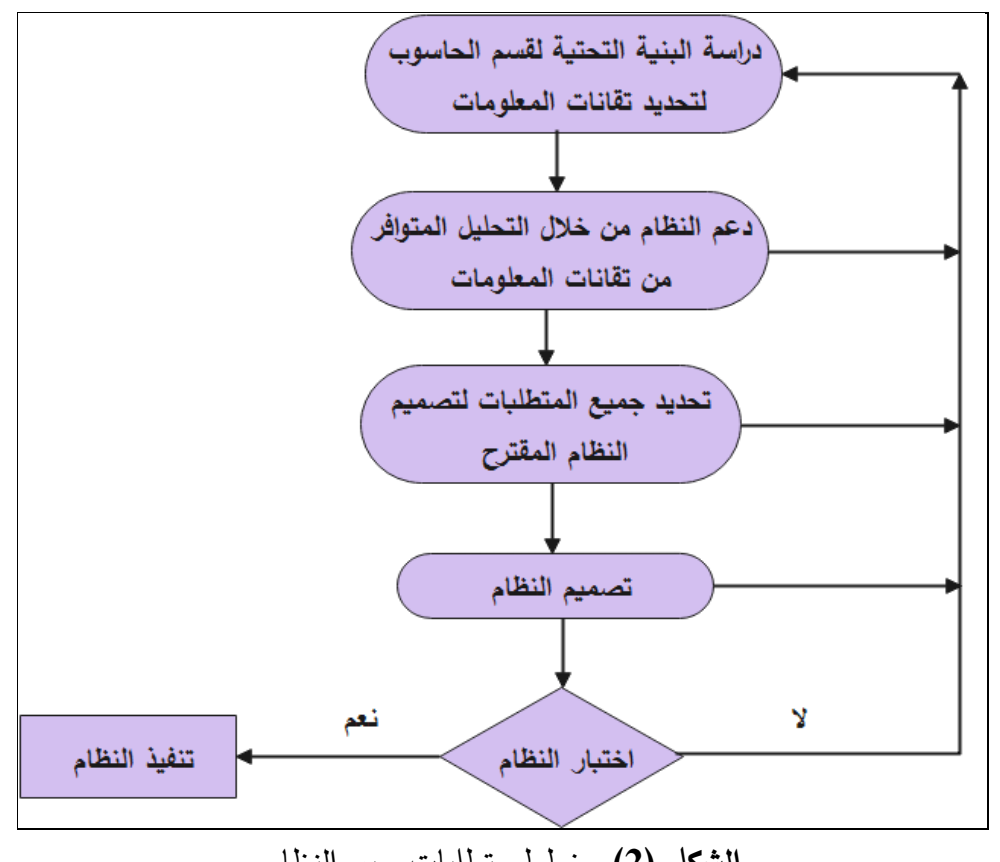

الشكل (2) مخطط متطلبات سير النظام

3se case تحليل بيانات النظام باستخدام مخطط استخدام الحالة

يتم تسليط الضوء في تصميم مخطط حالة الاستخدام على احتياجات النظام الحقيقية وتحديد آلية استخدامه إذ سيكون هناك أربع مستويات لمستخدمي النظام تم الفصل وتمييز مهام كل واحد منهم كما يلي: هُ المستوى الأول: المستخدم في المستوى الأول لديه كل الصلاحيات المطلقة في النظام وهي حذف اضافة تعديل استعراض وإدارة المستخدمين.

هُ المستوى الثاني: يمنح مدير النظام المستخدم في هذا المستوى عملية إدخال البيانات والتعديل عليها مع عملية الحذف أيضاً لكن لا يستطيع الاخول لأداره المستخدمين وتحديد مستوى الصدلاحيات. هـ المستوى الثالث: يمنح مدير النظام لمستخدم المستوى الثالث صلاحية أدخال البيانات والتعديل عليها لكن لا يمكنه من حذف تلك البيانات. 
هـ المستوى الرابع: يحدد مدير النظام المستخدم في هذا المستوى بعملية البحث واستعراض النظام فقط وليس لديه أي صلاحية اخرى. كما موضح في الشكل (3) استخدام الحالة Use Case أدناه:

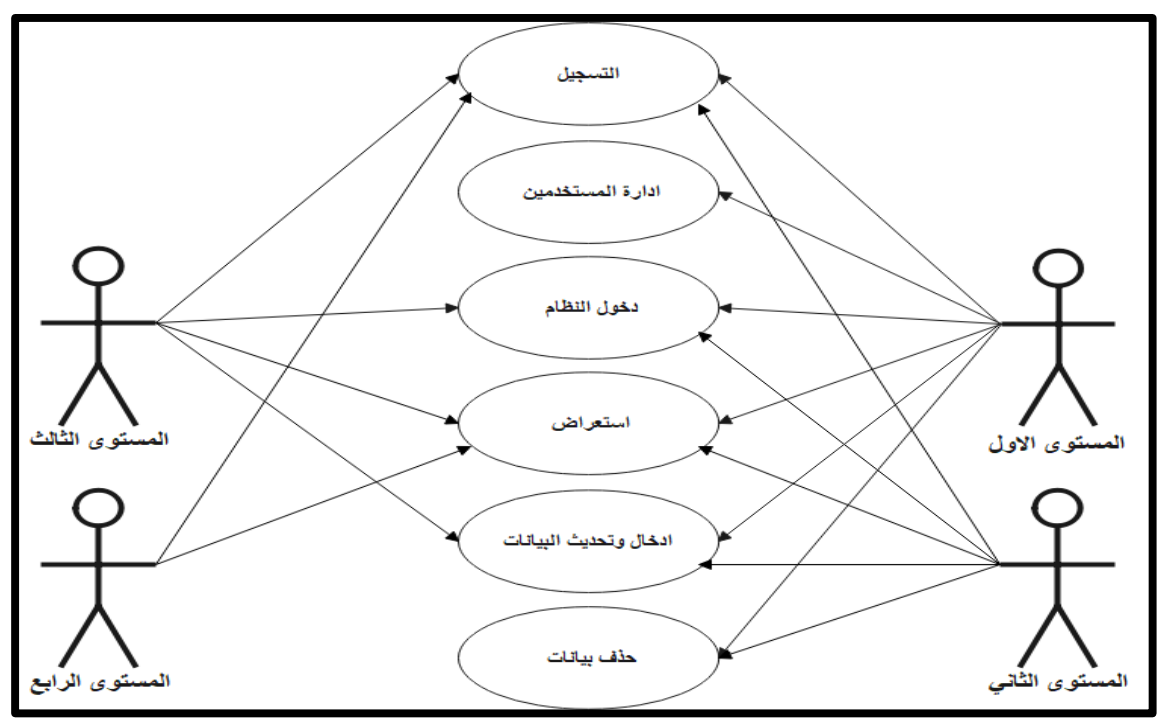

الثكل (3) مخطط استخدام الحالة للمستويات الاربعة

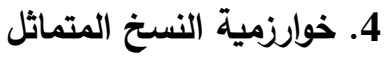

الهدف من استخدام النسخ المتماثل في نظام إدارة الرسائل والأطاريح الإلكتروني تجنباً لفقدان وتلف أو تضرر الرسائل والأطاريح الموجودة في قسم الحاسوب خاصةً بعد تعرض جامعة الموصل للأعمال الارهابية في السنوات القليلة السابقة وتضرر قسم الحاسوب من خلالها لذا ظهرت الحاجة للحفاظ على سلامة الرسائل والأطاريح التي تعتبر النتاج العلمي الذي قدمه اساتذة وطلاب هذا القسم فيتم المحافظة على نسخ احتياطية من النظام خارج بيئة العمل ليتم الوصول اليها في اي وقت. تم في هذا البحث تتفيذ عمليات النسخ المتماثل على قاعدة البيانات الخاصة بالنظام من خلال عدد من الخطوات والاجراءات التي تم اعتمادها بالاستتاد على نظام إدارة قاعدة البيانات SQL Server، تم اختيار عمليات نسخ متماثل من نوع Transactional والذي يتميز بخاصية تتفيذه بشكل دوري بالاعتماد على اي تغييرات تطرأ على

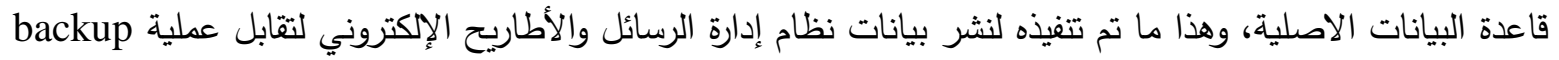
النسخ الاحتياطي واسترجاع البيانات Recovery للنظام الذي يجب ان يتم تتفيذه يدوياً. إن عمليات النسخ المتماثل تعتمد في الاساس على وجود قاعدة البيانات على اكثر من خادم لذلك تم في الخطوة الأولى تهيئة خادم جديد وربطه عبر الشبكة مع الخادم الأول الذي يضم قاعدة البيانات الاصلية، بعد ربط الخوادم تم في الخطوة الثانية نسخ قاعدة البيانات إلى الخادم الجديد، يعتبر وجود نفس قاعدة البيانات على اكثر من خادم شرطاً اساسياً لتتفيذ عمليات النسخ المتماثل التي تبدأ من الخطوة الثالثة في الخوارزمية وهي انثاء موزع بيانات على الخادم الأول وهذا الموزع يعمل كحلقة وصل بين الناشر والمتابع، نلاحظ في الخطوة الرابعة من الخوارزمية انشاء ناشر البيانات في الخادم

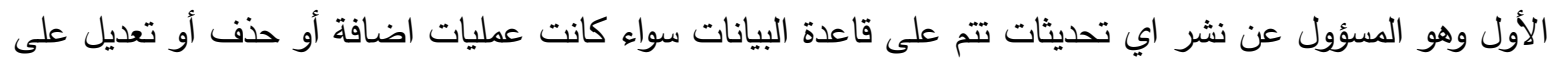
اي جدول من جداول قاعدة البيانات الاصلية، يتم ارسال التحديثات من الناشر إلى الموزع الذي يقوم بدوره بنقل التحديثات 
إلى المتابع الموجود في الخادم الجديد ليتم مطابقة النسخ المتماثل من خلال تفعيل خاصية المزامنة Synchronization

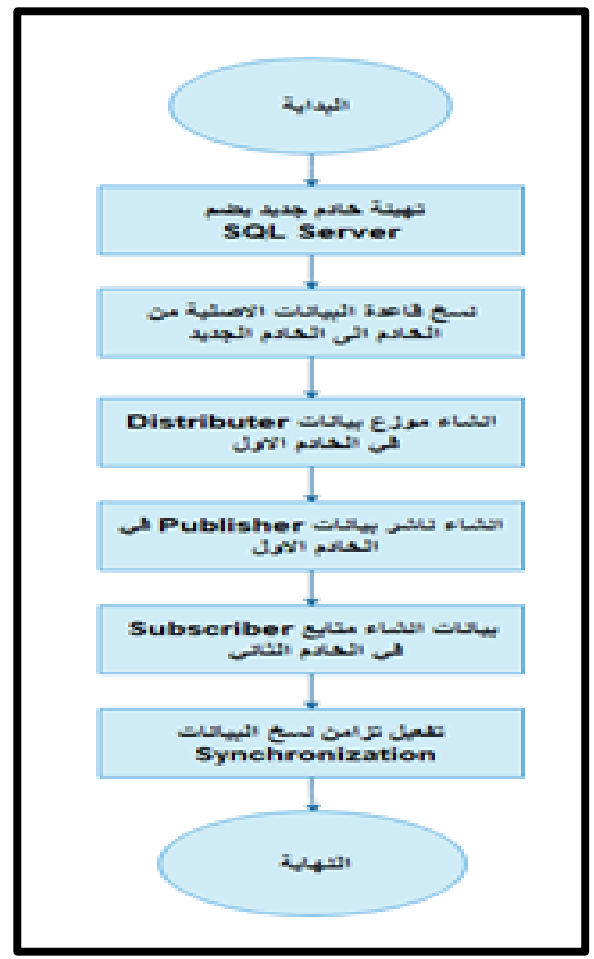

الثكل (5) خوارزمية النسخ المتماثل

5. 5 5 5 ملبات عمل النظام المقترح:

يتضمن نظام إدارة الرسائل مجموعة من المكونات وتترابط جميع هذه المكونات ليتم ادخال ومعالجة، حفظ، استرجاع المعلومات واجراء عمليات التحكم في الانشطة والمهام.

1.5 قاعدة بيانات: باستخدام أحد اشهر انظمة إدارة قواعد البيانات 2008 MS SQL Server تم تصميم وبناء قاعدة البيانات الخاصة بالنظام.

2.5 بناء واجهات لإدارة النظام: تم بناء النظام باستخدام لغة برمجة الواجهات 2012 على منصة وبمساندة البرمجيات Crystal Report و بمET. Framework) الرسائل.

6. المواصفات التشغيلية للنظام

تم اقتراح تصميم وبناء نظام إلكتروني لإدارة الرسائل والأطاريح في قسم الحاسوب يمتاز بجملة من الخصائص: 


\section{6 واجهة رسومية غير مققدة}

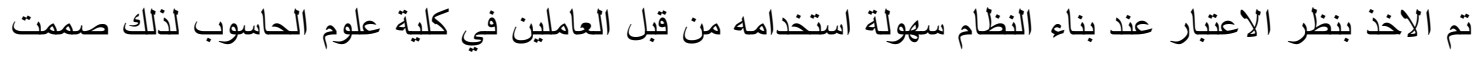
واجهات بسيطة لتمكين استخدامها بواسطة الأشخاص الذين لديهم معرفة بسيطة باستخدام الحاسوب.

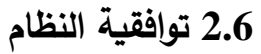

سهولة التعامل مع النظام من خلال تتفيذ جميع الإجراءات بدون صعوبة أو تعقيد وعمله بصوره مرنة مع برامج

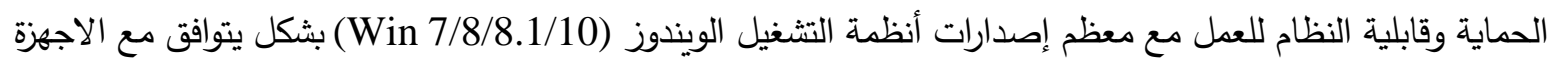

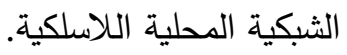
3.6 مستويات الحماية

هناك مستويان من الحماية للحفظ على النظام وسريته من التهديدات الداخلية والخارجية:

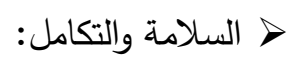

- إدارة النظام تكون الوحيدة التي لديها الحق في تعديل معالم النظام.

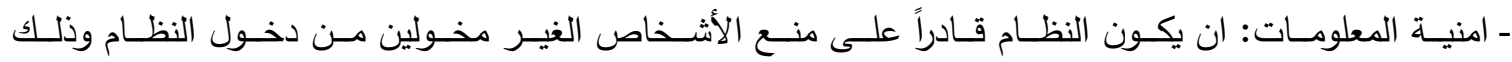
بإنخال اسم المستخدم وكلمة المرور الخاصة بالمخول وتحديد مستوى الصلاحيات للمستخدمين. - صحة المعلومات وعدم ضياعها في حال حدوث خطأ أو عطل.

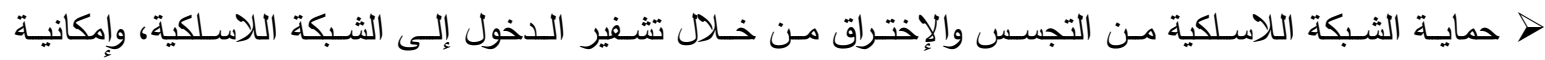

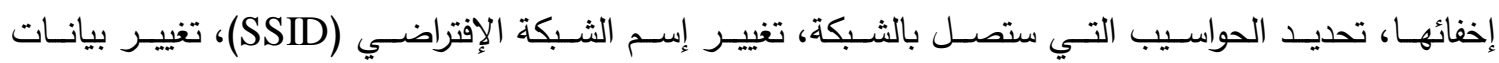

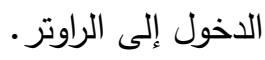

\section{تصفح واجهات النظام المقترح}

يتألف النظام من عدة شاشات (Form) الأولى خاصة بثاشة الدخول إلى النظام يليها الثاشة الرئيسية بالنظام إدارة

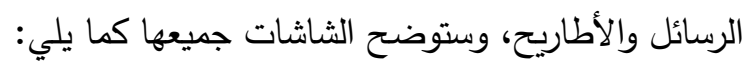

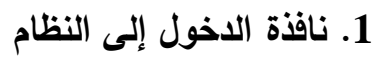
في بداية التثغيل تظهر ناففة تسجيل الدخول المبينة في الثكل (6) ويتم الولوج اليها حسب مستوى الصلاحيات

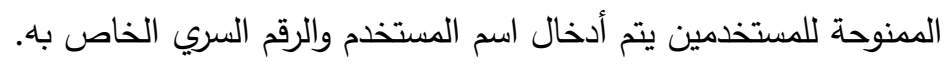




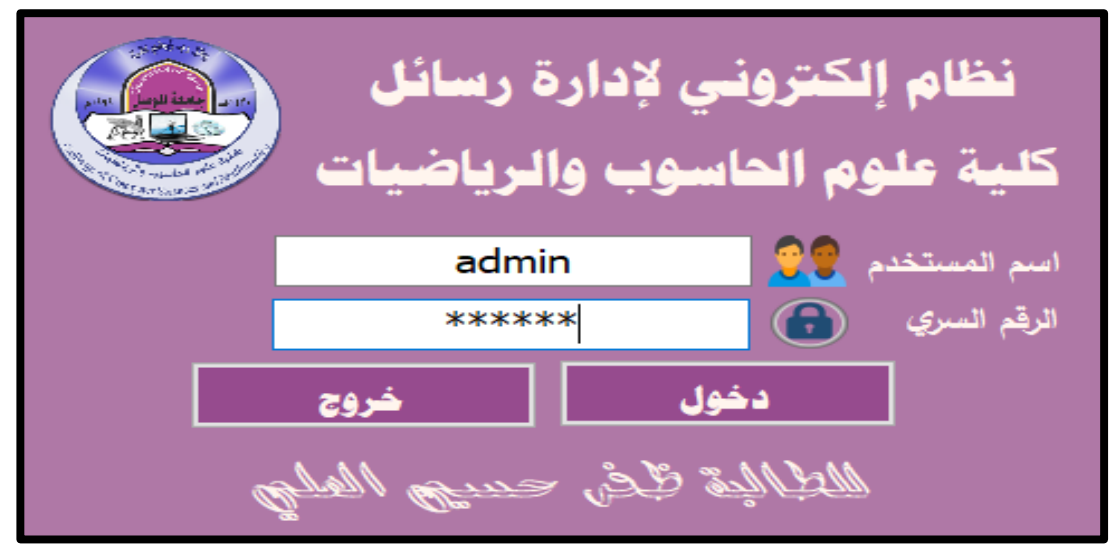

الثكل (6) نافذة الدخول إلى النظام

2. النافذة الرئيسة

تضم النافذة الرئيسية الموضحة في الثكل (7) زر إدارة الرسائل والأطاريح الذي يقوم بنقلنا إلى الاجزاء الرئيسية للنظام وزر إدارة المستخدمين وزر خروج عند انتهاء العمل من النظام.

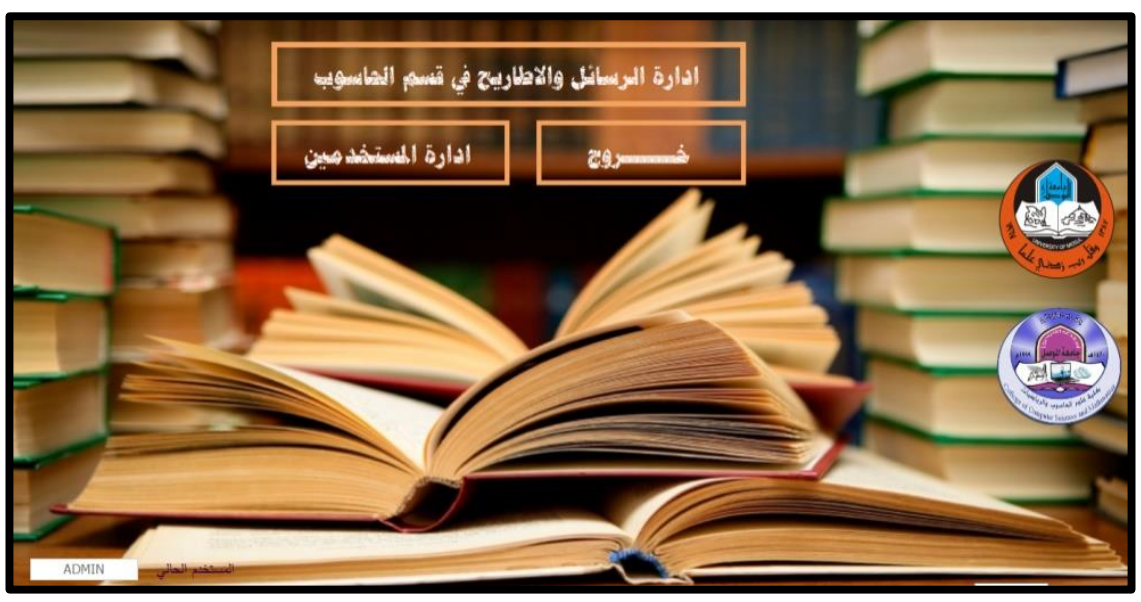

الثكل (7) النافذة الرئيسة

3. 3 إدارة المستخدمين

مدير النظام هو الثخص الوحيد المصرح له الدخول إلى شاشة إدارة المستخدمين المبينة في الثكل (8) ادناه التي من خلالها يقوم بإدارة المستخدمين إذ يعمل على إنشاء اسم المستخدم والرقم السري وتحديد مستوى الصلاحية لمستخدمي النظام إن كان مخول أو متصفح فقط. 


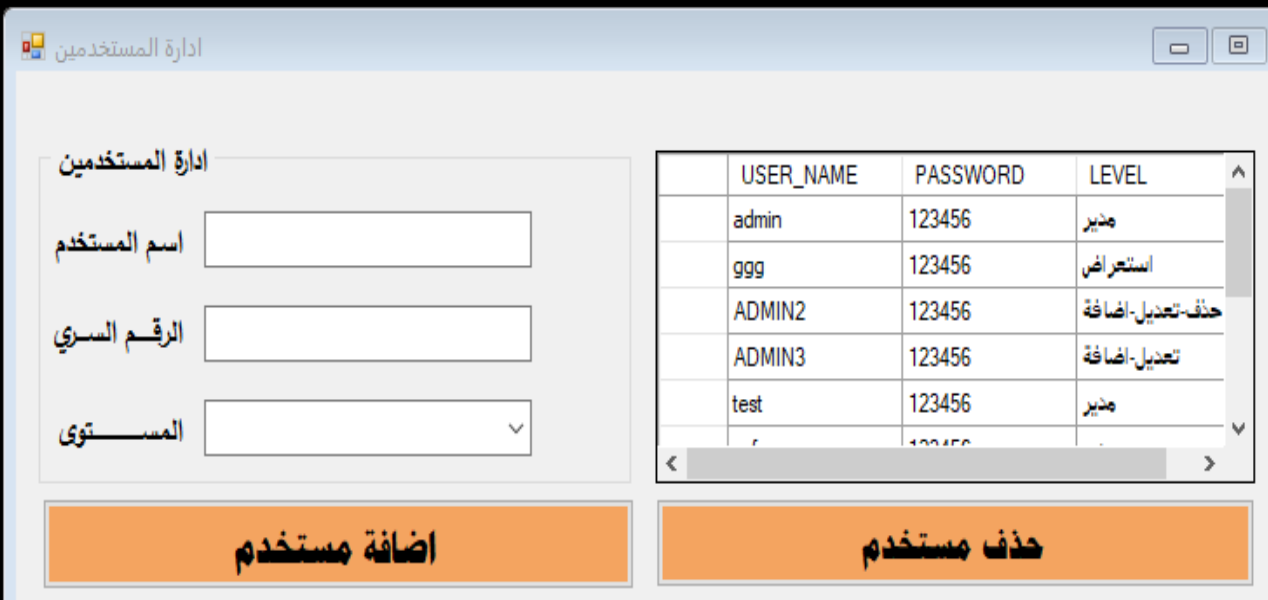

الثكل (8) شاشة إدارة المستخدين

4. شاشة الدراسات العليا

تحوي هذه الثاشة والموضحة في الثكل (9) على عدة ازرار والتي تشمل كافة بيانات التي تخص الدراسات العليا.

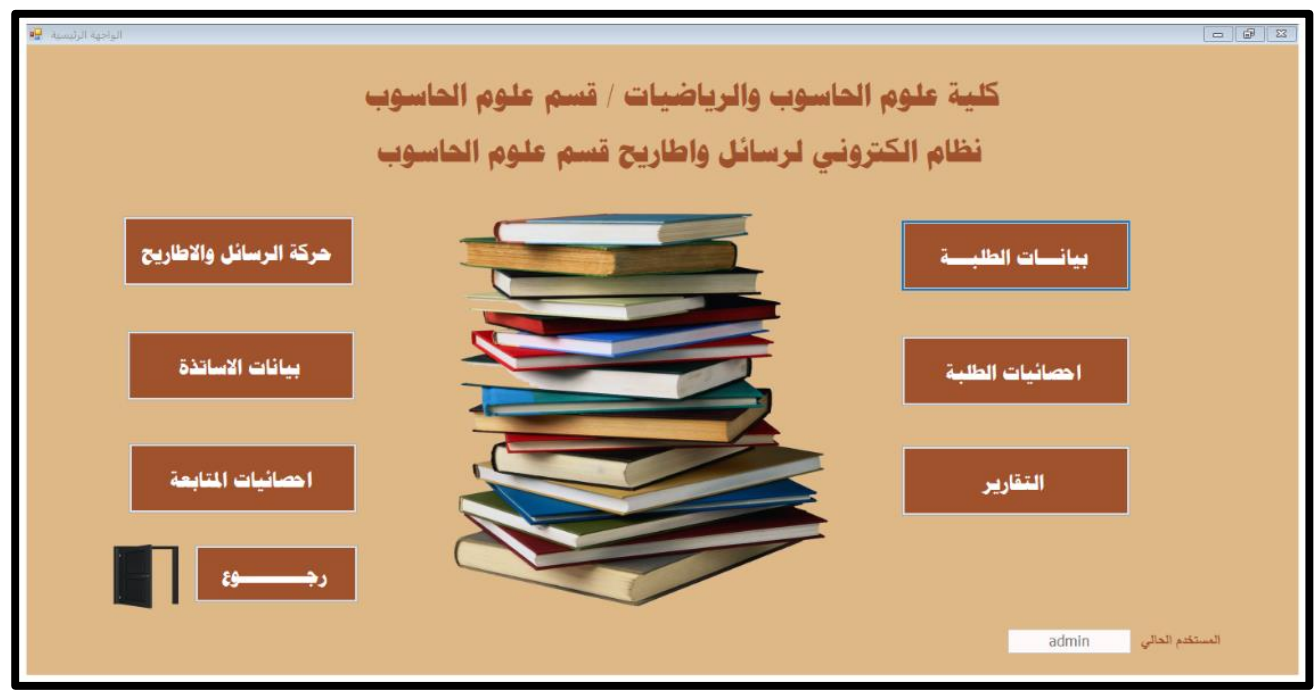

الثكل (9) شاشة الدراسات العليا

5. تحركة الرسائل والأطاريح

تحوي هذه الثاشة والموضحة في الثكل (10) على كافة البيانات الخاصة بالرسائل والأطاريح الموجودة في قسم الحاسوب مع ملف الرسالة إذا كانت مكتملة. 


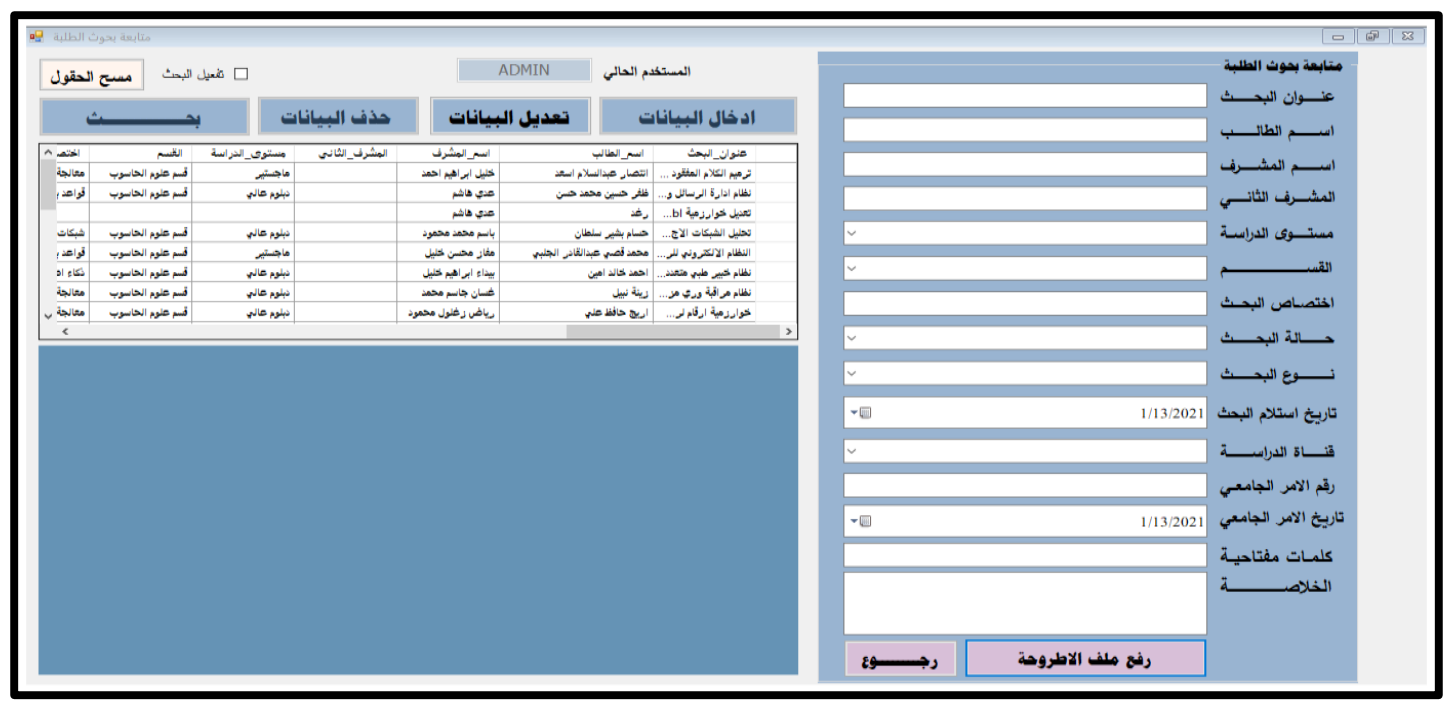

الثكل (10) نافذة بيانات الاطروحة

6. نافذة بيانات الاساتذة

عند الضغط على زر بيانات الاساتذة الموجود في نافذة الدراسات العليا ستقتح للمستخدم نافذة اساتذة قسم الحاسوب

$$
\text { الموضحة في الشكل (11) التالي: }
$$

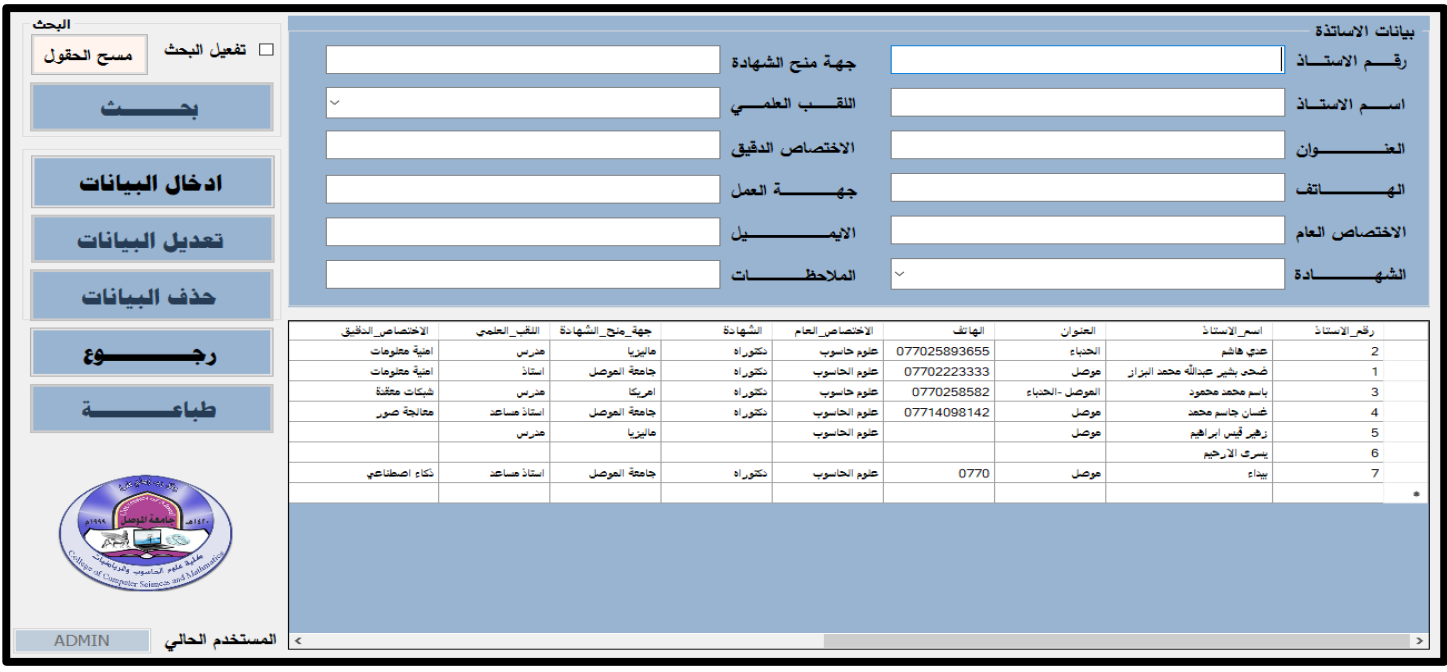

الشكل (11) واجهة بيانات الأساتذة

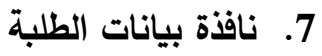

تحوي هذه الواجهة عدة حقول وأزرار تملأ لتكون قاعدة بيانات شاملة بجميع المعلومات الخاصة بطالب الدراسات العليا موضحة في الثكل (12) التالي: 


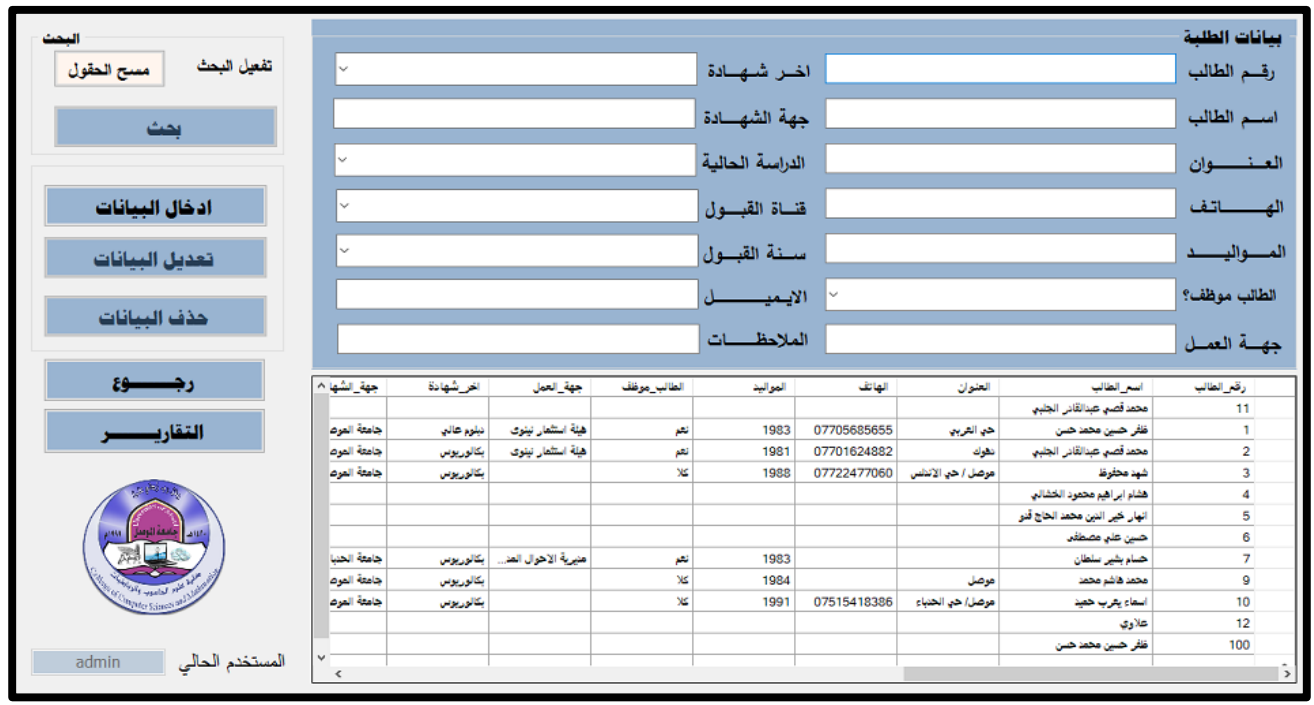

الثكل (12) نافذة بيانات الطلبة

8. احصائيات المتابعة

توضح هذه الواجهة الموضحة في الثكل (13) احصائيات حالة البحث. الإحصائية الأولى توضح حالة البحث بالنسبة لطلبة الدبلوم العالي، اما الاحصائية الثانية لطلبة الماجستير والاخيرة لطلبة الدكتوراه.

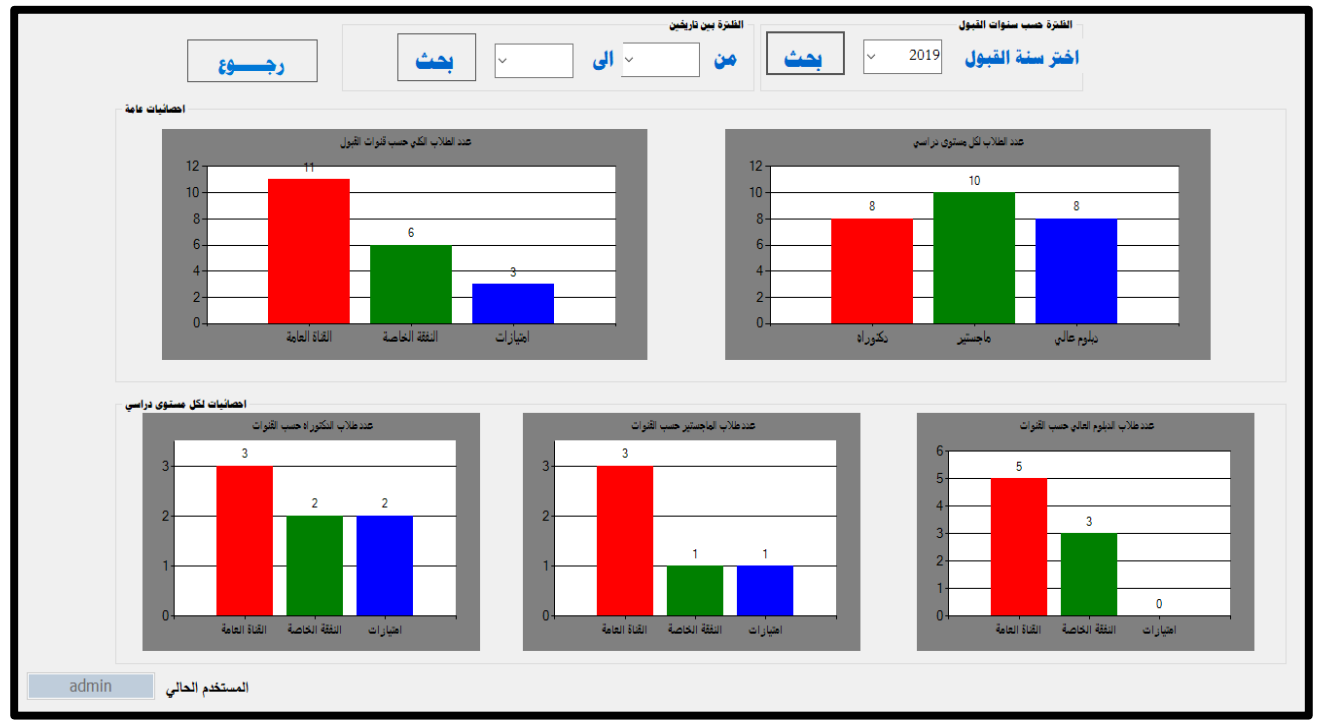

الثكل (13) احصائيات الطلبة

9. احصائيات حالة البحث:

تضم هذه النافذة الموضحة في الثكل (14) احصائية عن حالة البحث ان كان في مرحلة البحث أو في مرحلة التسليم أو كان مكتملاً مع عددها ولكل دراسة (دبلوم عالي- ماجستير - دكتوراه). 


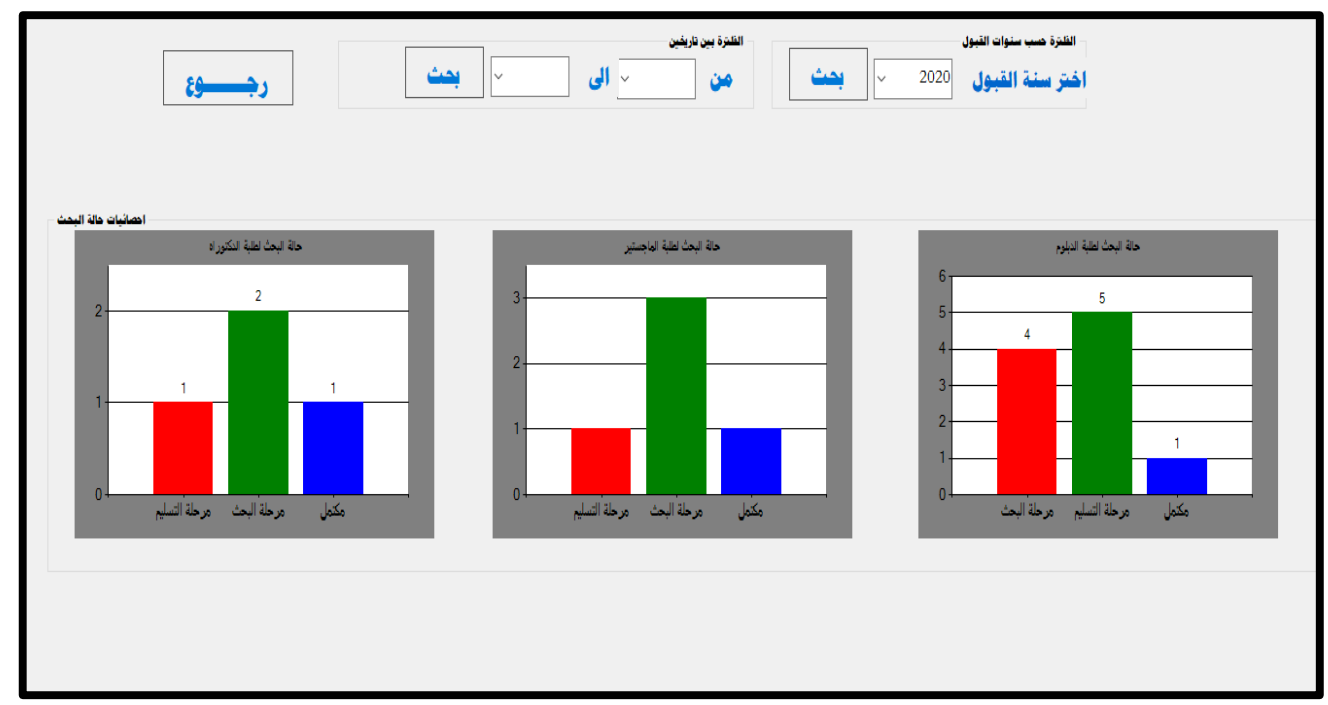

الشكل (14) إحصائية حالة البحث

10. التقارير

يقدم النظام تقارير منوعة عن الطالب والأستاذ أو عن البحوث المتوفرة في النظام وبياناتهم تساعد الموظف المختص من طباعة التقارير وتقديمها لرئاسة القسم حال طلبها، والاشكال (15)(16)(17)(18) التالية توضح هذه التقارير :

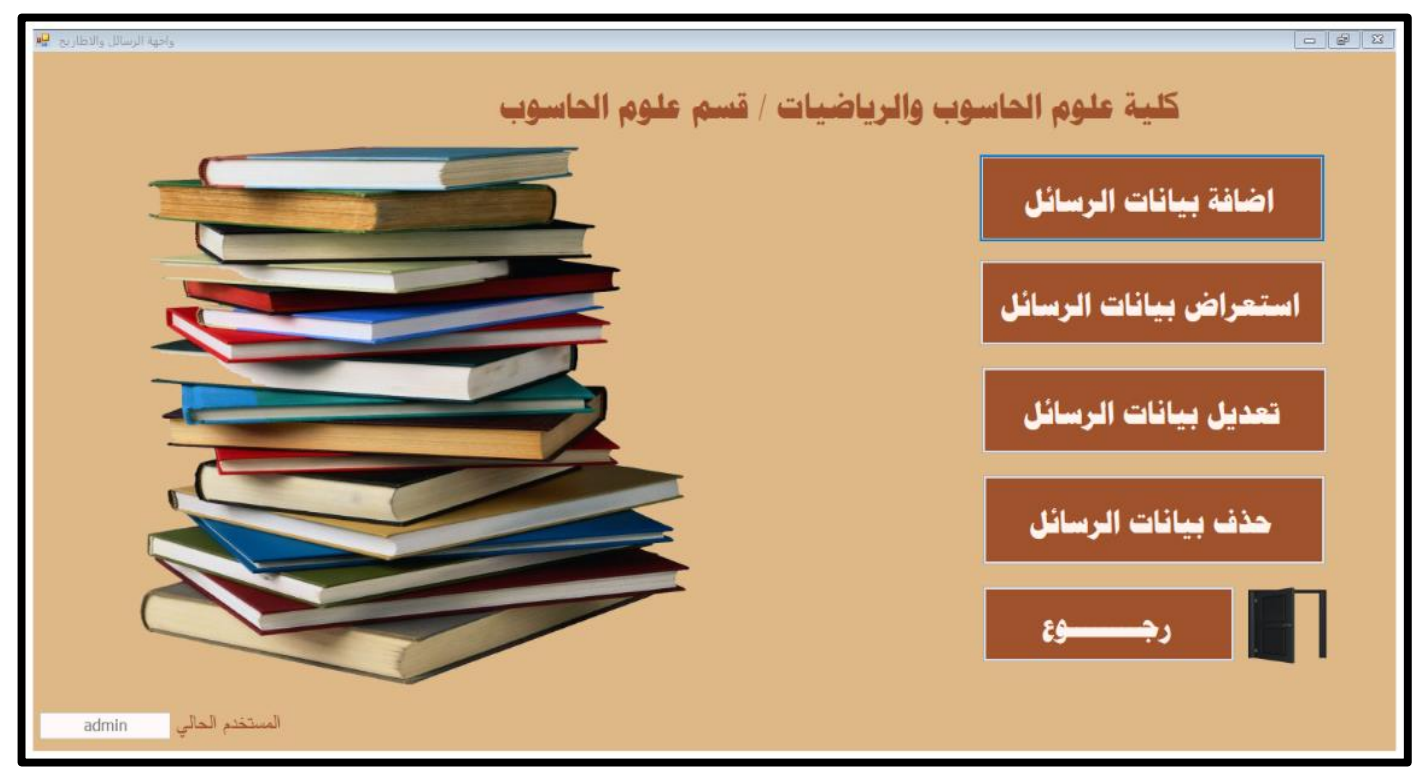

الثكل (14) نافذة التقارير 


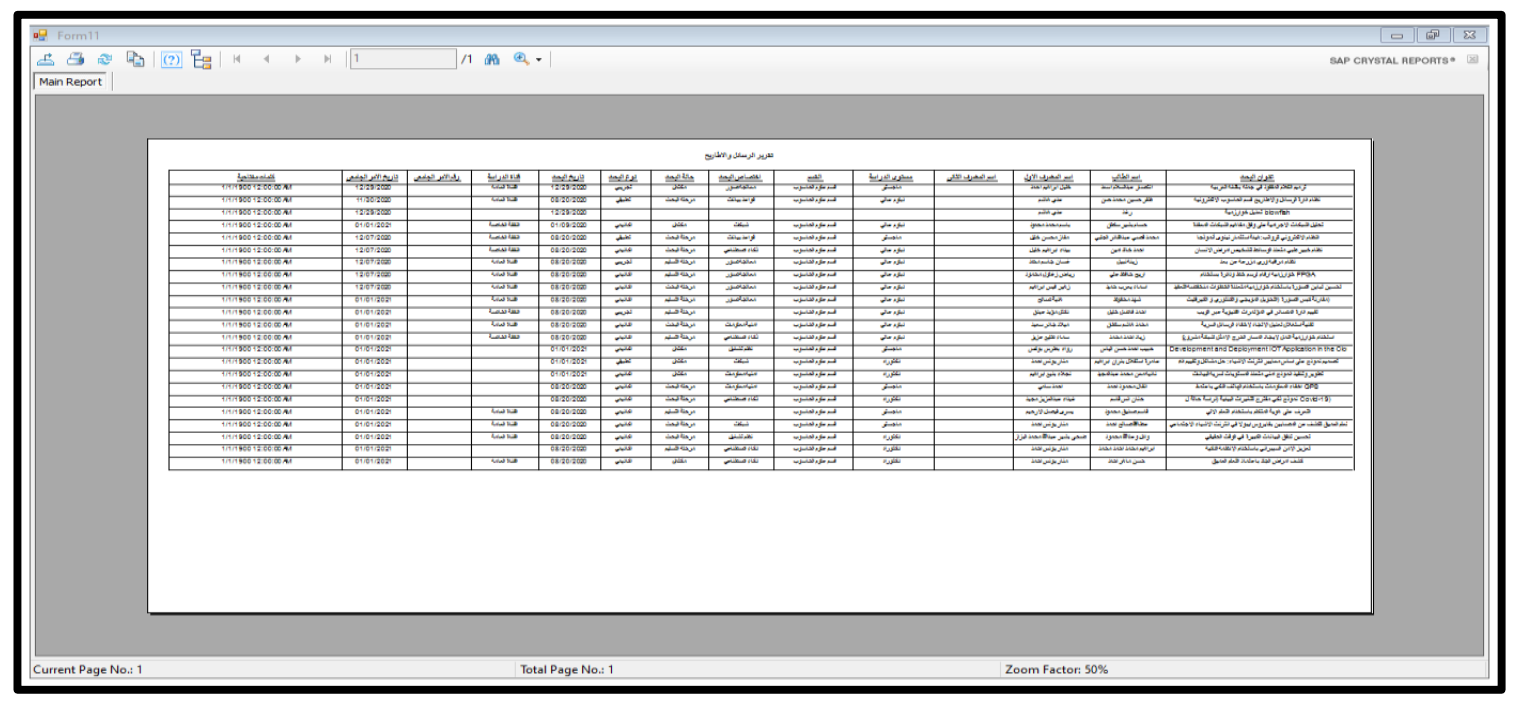

الثكل (15) تقارير الرسائل والأطاريح

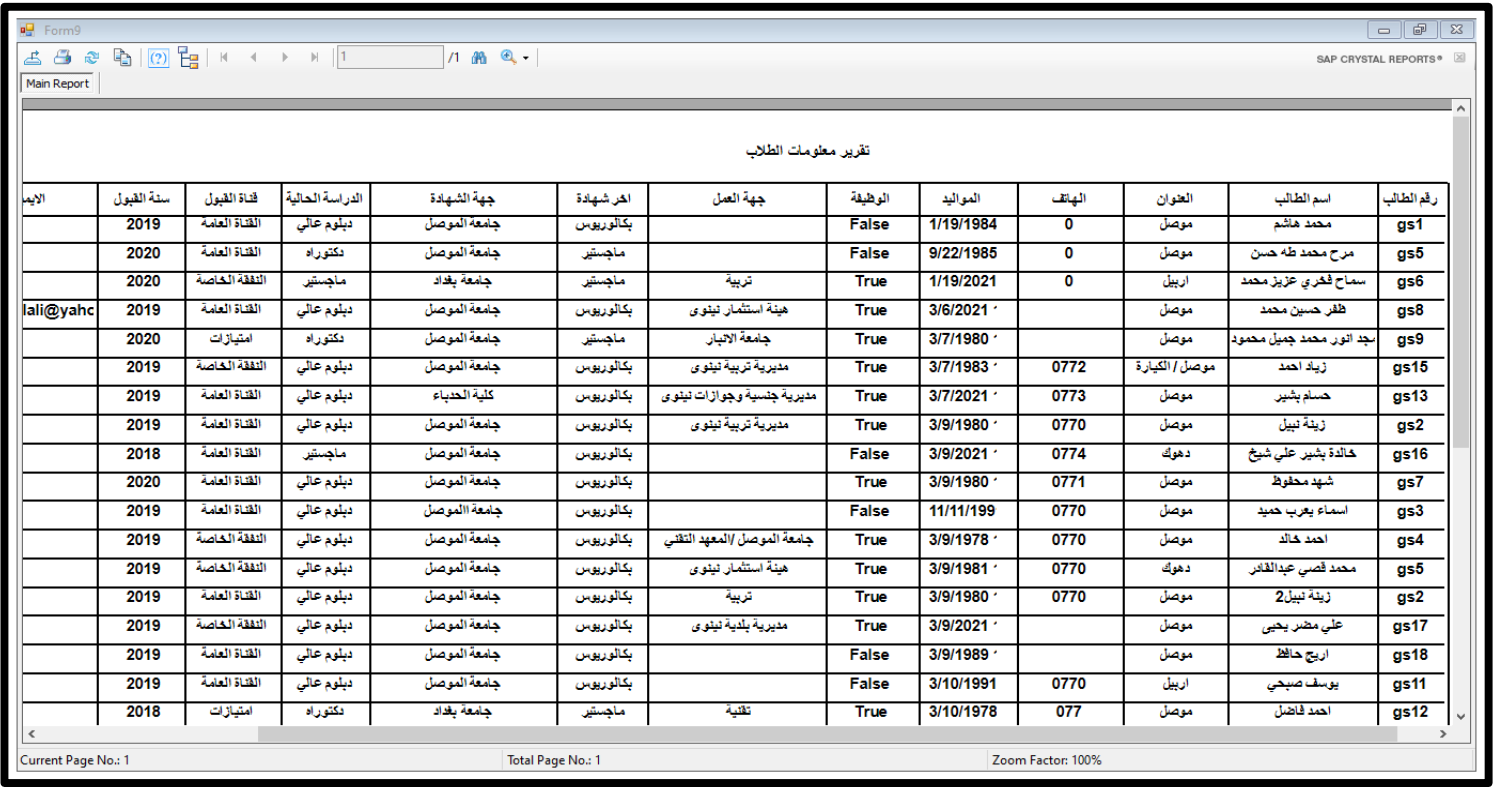

$$
\text { الثكل (16) تقارير الطلبة }
$$




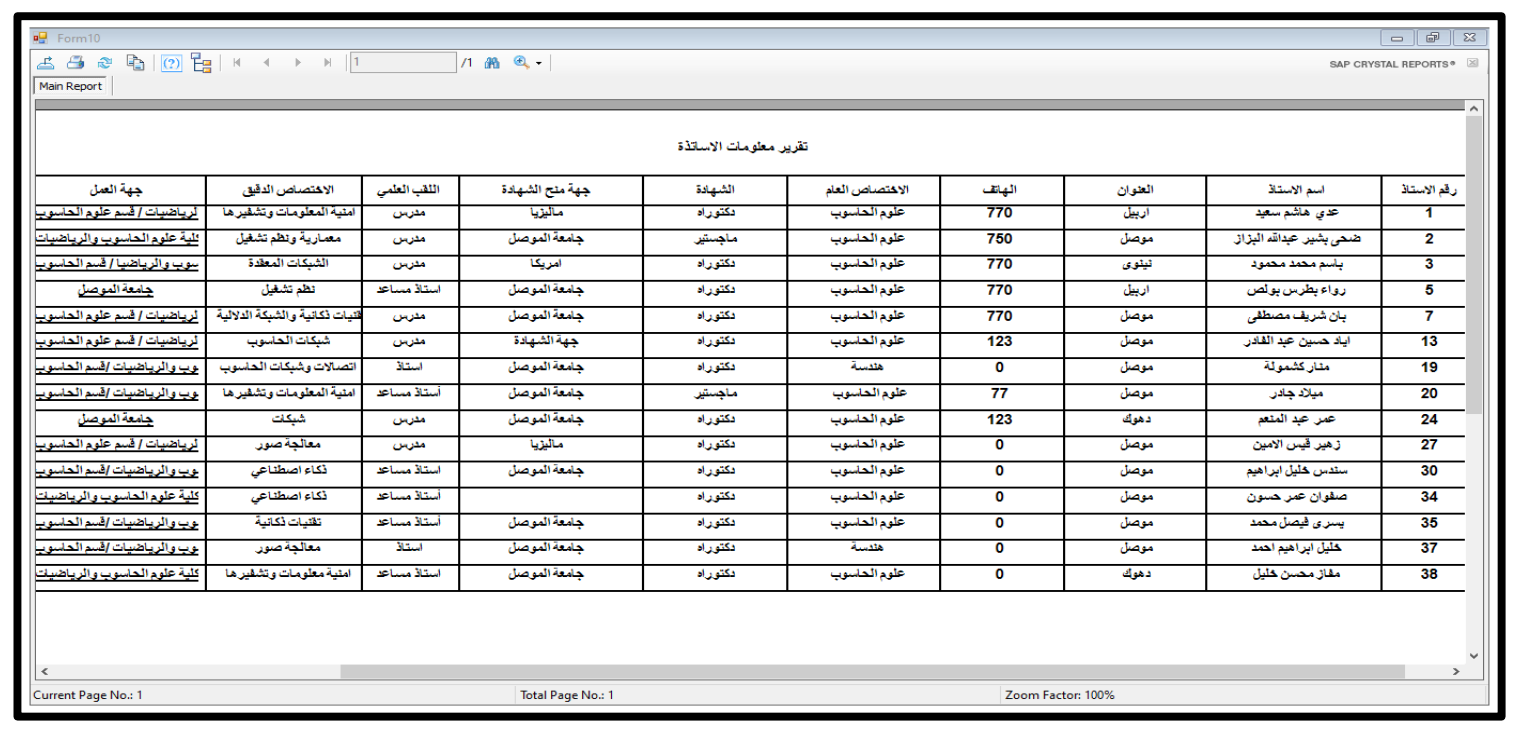

$$
\text { الشكل (17) تقرير معلومات الأستاذ }
$$

11. الاستنتاجات

توصل البحث بالاعتماد على ما سبق إلى استخلاص مجموعة من الاستتتاجات مبينة كالتالي: 1- ان هناك عدة دوافع لتطبيق نظام إدارة الرسـائل والأطاريح الإكتروني في كلية علوم الحاسـوب منها الفائدة المتاحة

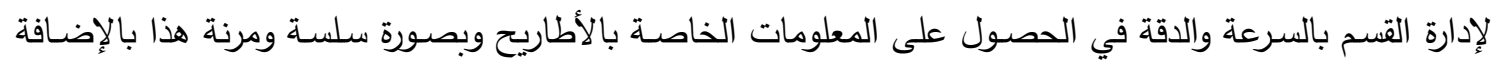
إلى المنفعة العلمية التي يمكن ان يمنحها هذا النظام لطلبة الدراســات العليا من ناحية توفير الأطاريح والرســـائل المنجزة في القسم وسهولة الوصول لها وسرعة البحث والاسترجاع، والارتقاء بمستوى البحث العلمي، وتوفير الحيز المكاني. 2- وفرت تقنية النســخ المتماثل أهمية خزن قاعدة البيانات في أكثر من موقع تلافياً لتضــرر بيئة العمل وفقد بياناتها وأغنت عن عملية الـ back up للنظام. 3- حفظ بيانات الطالب والأستاذ والاطروحة في قاعدة بيانات واحدة ضمن نظام (MS SQL Server) لضمان سرية

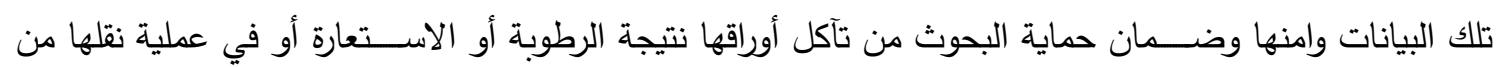
مكان لآخر . ماني

4- حماية النظام باسـتخدام الحسـابات المختلفة من اسـماء ورمز المرور خاصــة بكل مسـتخدم لمنحه صــلاحية دخول

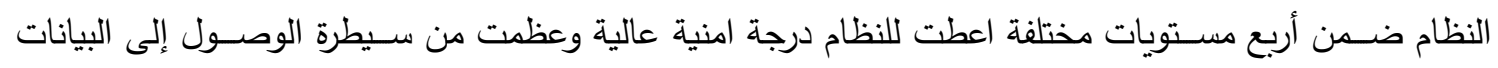
بتحديد المخولين. 5- امكانية اجراء عملية البحث في جميع حقول الموجودة في النظام وهذا مـا يميز نظام إدارة الرســـائل والأطاريح الإكتروني عن باقي الانظمة التي تكون مقتصرة على البحث في حقول محددة أو حسب كلمات مفتاحية. 
6- اثبت اسـتخدام برنامج Crystal Report ســهولة اعداد التقارير الخاصــة بكل من الطالب، الأســاذ والاطروحة وطباعتها فضـلاً عن توفير مؤشرات رقمية على شكل مدرج تكراري تساعد رئاسـة القسم واللجنة العلمية على توفير احصائيات متنوعة.

\section{2. التوصيات للأعمال المستقبلية}

بعد إتمام انجاز نظام الإدارة الإكترونية للرسائل والأطاريح في قسم علوم الحاسوب وتطبيقه تم صياغة بعض التوصيات التي منع من تصميمها وتتفيذها في النظام ضيق الوقت وكبر مكونات وحجم النظام وبالإمكان اضافتها مستقبلا ضمن الاعمال المستقبلية لبحوث طلبة الدراسات العليا من حيث إضافة خصائص وامكانيات جديده تتلائم مع تطور التقنيات في الجامعة والقسم مستقبلا. يمكن اجمال اهم الاعمال المستقبلية التي تم التوصل اليها خلال العمل بالنقاط

1- امكانية تطوير النظام ليشــل جميع رســائل وأطاريح جامعة الموصـل ومن ضــــها اقــام كلية علوم الحاسـوب والرياضيات ليكون كمكتبة شاملة تضم جميع البحوث العلمية والتي ممكن ان تشمل جميع المستويات ومنها بحوث تخرج طلبة الدراسات الأولية.

2- تطوير النظام عن طريق امكانية تحويله إلى تطبيق موبايل ليتسـنى اســتخدامه والتحكم به من اي مكان ومن اي جهاز محمول.

3- تطوير النظام من خلال اضــافة امكانية التوثيق الإلكتروني بربط النظام بجهاز الماســح الضـــئي لإرفاق البحث

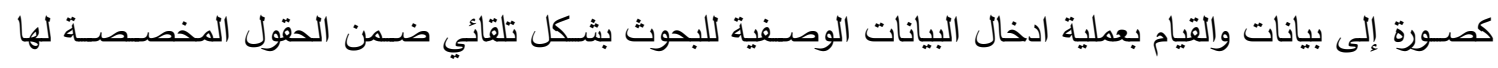
باستخدام تطبيق التعرف على النصوص اثثاء عملية المسح الضوئي. 
|'مصادر

الجدعاني، يسرى محمد، (2011)، الارشفة الإكترونية للرسائل الجامعية في مكتبة جامعة الملك عبد العزيز :

دراسة حالة، رسالة ماجستير، علم المعلومات، كلية الآداب والعلوم الإنسانية، جامعة الملك عبد العزيز ، المملكة

العربية السعودية.

عبداوي، هناء، (2016)، مساهمة في تحديد دور تكنولوجيا المعلومات والإتصالات في إكساب المؤسسة ميزة

تتافسية - دراسة حالة الشركة الجزائرية للهاتف النقال موبيليس، ص (49)، أطروحة دكتوراه، كلية العلوم

الإقتصـادية والتجارية وعلوم التسيير قسم علوم التسيير ، جامعة محمد خيضر - بسكرة، الجزائر .

السيد، مازن محمد إبراهيم، (2016) ، وفي عام 2016، بناء نظام إلكتروني لإدارة الأوراق العلمية لكلية الدراسات

العليا بجامعة النيلين، رسالة الماجستير ، جامعة النيلين، السودان.

بشير، مروة زيدان، فرج، سامية أحمد، (2017)، تصميم نظام مكتبة رقمية كلية العلوم/ جامعة سبها، رسالة

$$
\text { بكالوريوس، قسم الحاسوب، كلية العلوم، جامعة سبها. }
$$

جاسم، عواطف صابر، حميد، اياد سعدي، حاجم، وسام إبراهيم، الجميلي، أمجد حسين جاسم، (2018)، دليل كتابة رسائل وأطاريح الدراسات العليا، جامعة تكريت، ص صدابر، (1-11).

عودة، كاظم زغير، عبد الله، فضل عبد الرحيم، (2019)، نظم المعلومات وأثرها على اتجاهات الباحثين في

مجال الاعلام بناء قاعدة بيانات لرسائل وأطاريح كلية الاعلام في جامعة بغداد للفترة من 2015/2005، مجلة آداب المستتصرية، العدد 85، الصفحة 232-252، جامعة بغداد. الموقع الرسمي لوزارة التعليم العالي والبحث العلمي، /https://www.rdd.edu.iq..

[8] Por, Lip Yee, Ong, Sim ying, Beh Delina, Ismail, Maizatul, (2010), Faculty of Computer Science and Information Technology, university of Malaya, Malaysia, The International Arab Journal of Information Technology, Vol. 9, No. 4.

[9] Franco, Geanne Ross 1, De Guzman, Carlo Ysmael C, (2016), Design and Implementation of a Web-Based Thesis Coordinator System (TCS), International TENCON Conference, CT Dept. of De la Salle University, Manilla, Philippines.

[10] Putra, Jati, Yuliana, Sukiman, Waisen, Awan, Benny, (2020), Data Management System for Thesis Monitoring at STMIK IBBI Using B-Model, $3^{\text {rd }}$ International conference on mechanical, Electronics, Computer, and Industrial Technology (MECnIT), Medan, Indonesia.

[11] Bose, Michael, how to Configure MS SQL Server Replication: Complete Walkthrough, (2020).

[12] SQL Server Replication: Full Overview and Step-By-Step Configuration (nakivo.com). 